\title{
Arterial Stiffness in Aortic Stenosis and the Impact of Aortic Valve Replacement
}

\author{
Oscar Plunde $\mathbb{D}^{1,2}$, Magnus Bäck (DD ${ }^{1,2}$ \\ ITranslational Cardiology, Department of Medicine Solna, Karolinska Institutet, Stockholm, Sweden; ${ }^{2}$ Department of Cardiology, Karolinska \\ University Hospital, Stockholm, Sweden
}

Correspondence: Magnus Bäck, Department of Cardiology, Karolinska University Hospital, M85, Stockholm, I4I 86, Sweden, Tel +46 8 585 800 00, Email magnus.back@ki.se

\begin{abstract}
The most common cause for interventional valve treatment is aortic stenosis. A cardinal symptom of aortic stenosis is heart failure due to the increased load exerted on the left ventricle. However, the left ventricular load is not solely determined based on the degree of aortic stenosis but is also impacted by arterial stiffness. The combined load can be determined by valvulo-arterial impedance (Zva), which is associated with poor outcome in aortic stenosis. We recently demonstrated low measures of systemic arterial stiffness in patients with aortic stenosis, and that arterial stiffness was increased after surgical aortic valve replacement. The results indicated a masked arterial stiffness in aortic stenosis when using methods incorporating peripheral arterial segments. Available studies using several different methods to assess arterial stiffness in relatively small aortic stenosis cohorts examined before and after either surgical or transcatheter aortic valve replacement/intervention have generated contradictory results. In this commentary, we present a detailed literature review to explore how different methods and measures of arterial stiffness in aortic stenosis capture or not, a masked arterial stiffness in aortic stenosis and possible reasons for the observed results. Future studies validating a non-invasive reproducible method to assess arterial stiffness in aortic stenosis patients could potentially lead to an implementation in pre-interventional risk assessment for aortic stenosis.
\end{abstract}

Keywords: aortic stenosis, arterial stiffness, pulse wave velocity, cardio ankle vascular index, valvular heart disease, ventriculararterial coupling

\section{The Importance of Arterial Stiffness in Aortic Valve Stenosis}

The importance of increased afterload in aortic stenosis has long been acknowledged and the vascular component of the afterload is receiving emerging attention. A stiffened arterial tree confers risk of damage to organs including the heart and independently predicts all-cause mortality. ${ }^{1}$ The combined left ventricular (LV) load may be assessed by transthoracic echocardiography determined valvulo-arterial impedance (Zva), which is independently associated with poor aortic stenosis outcome. ${ }^{2}$ However, Zva cannot discriminate the valvular and arterial respective contribution, raising the notion that direct measurement of arterial stiffness would represent additional value in aortic stenosis evaluation. Indeed, increased measures of arterial stiffness have been associated with aortic valve calcium, ${ }^{3}$ aortic valve sclerosis, ${ }^{4}$ aortic stenosis ${ }^{5}$ and poor prognosis after aortic valve replacement. ${ }^{6}$ However, the effect of aortic valve replacement on arterial stiffness, although studied, remains to be clinched. We recently reported that arterial stiffness was normal or low in patients with aortic stenosis but increased to pathological measures after aortic valve replacement surgery. ${ }^{7}$ Thus, alleviation of the LV outflow obstruction could unmask an increased arterial stiffness. In this commentary, we have made a detailed literature review to explore how methods may capture or not the masked arterial stiffness in aortic stenosis.

\section{Methods to Determine Arterial Stiffness in Aortic Valve Stenosis}

In addition to the gold standard method to measure arterial stiffness, carotid femoral pulse wave velocity ${ }^{8}$ (cfPWV), several other methods are used with specific advantages and disadvantages. However, few studies of arterial stiffness 
have been performed in valvular heart disease. Studies that assessed arterial stiffness before and after either surgical aortic valve replacement (SAVR) or transcatheter aortic valve intervention (TAVI) are outlined in Table 1.

\section{Aortic Stiffness Index}

Early studies used echocardiography to determine aortic stiffness index (ASi) by the relation between blood pressure and change in the ascending aortic diameter. The ASi studies reported contradictory results with a tendency towards decreased stiffness when measured $>3$ weeks after TAVI but increased stiffness 7 days after SAVR. ${ }^{9-12}$ Of importance, ASi only measures the stiffness in a small area of the ascending aorta and limited conclusions may be drawn about the overall arterial stiffness. Furthermore, the results indicate a distinctive response depending on intervention which is supported by studies using cardiac magnetic resonance imaging (cMRI) to calculate PWV. ${ }^{13}$ Some have argued that this might be due to the surgical trauma, disrupting vasa vasorum and causing aortic stunning. However, we have demonstrated that arterial stiffness measured by cfPWV, brachial ankle (ba) PWV and cardio-ankle vascular index (CAVI) remain unaltered in patients undergoing surgery for ascending aortic dilatation in the absence of aortic stenosis. ${ }^{7}$

\section{Oscillometric Based Pulse Wave Velocity}

The Mobile-O-Graph utilizes an oscillometric brachial cuff to measure blood pressure and pulse wave analysis yielding augmentation index (AIx) and PWV, termed oscillometric PWV (oPWV). Two studies used this method of which one noted decreased oPWV 1 day after TAVI and another unchanged oPWV 90 days after SAVR. ${ }^{14,15}$ However, concerns have been raised based on a study showing that $99.1 \%$ of the variation in oPWV was explained by age and systolic blood pressure. ${ }^{16}$ Also, a considerable discrepancy between oPWV and cfPWV was observed in a Marfan $\operatorname{cohort}^{17}$ indicating that oPWV may need validation in specific populations.

\section{Augmentation Index}

The invasive measurement of arterial stiffness using pressure wires offers a robust assessment of aortic pressure waves that can be used to calculate AIx. However, only two studies have used this technique and despite using similar cohorts, reached conflicting results. ${ }^{18,19}$ Although invasive pressure techniques might be feasible in the AVR setting, we argue that a non-invasive method is preferred to assess the arterial stiffness as part of the preoperative risk assessment. Noninvasive AIx measurement has been used in 2 studies, which showed decreased AIx after AVR. ${ }^{20,21}$ The reason for this decrease is likely explained by the arguments that Pagolatou et al outlined. ${ }^{19}$ First, the timing of the reflective wave changes after the relief of the aortic stenosis implies that the relative contribution of the reflective wave decreases leading to a lowering of AIx. Second, wave separation analysis did not demonstrate a decrease in the reflective pressure wave which would be expected if explained by decreased arterial stiffness. ${ }^{19}$

\section{Pulse Wave Velocity and Cardio Ankle Vascular Index}

As opposed to AIx, cfPWV uses the foot of the wave to detect the arrival of the pulse wave. Hence, the method should be less sensitive to the prolonged arterial pressure curve in aortic stenosis. Three previous studies incorporating both TAVI and SAVR subjects demonstrated an increased cfPWV after AVR. ${ }^{21-23}$ However, two studies, including ours, did not reach a statistically significant increased cfPWV. ${ }^{7,24}$ This might be due to lack of power as the increase is rather small and that the inter-observer variability of the Sphygmocor device is about $9 \% .{ }^{25}$ Building on the same principle as measuring cfPWV, both baPWV and CAVI determined arterial stiffness including peripheral segments. Two studies reported an increase in baPWV following AVR with our study demonstrating a similar CAVI response. ${ }^{7,21}$ It is important to stress that proximal stiffness affects the valve hemodynamics leading to increased Zva and therefore, we argue that it is of value also to include peripheral segments when determining arterial stiffness in aortic stenosis patients.

The reason for an increased peripheral arterial stiffness following AVR is likely to involve the previously mentioned prolonged pulse wave in aortic stenosis. The change in ejection time was one of the strongest predictors of the increase in CAVI in our study where a decreased ejection time was associated with a more pronounced increase in CAVI. ${ }^{7}$ When the propagation of the pulse wave is prolonged, arteries may comply better to the volume change causing a prolongation of time to detection of the pulse wave. Pulse wave analysis ${ }^{18}$ and decreased upstroke time ${ }^{7}$ support 
Table I Studies of Arterial Stiffness in Aortic Valve Stenosis

\begin{tabular}{|c|c|c|c|c|c|c|}
\hline Study & Cohort & Change in SBP & Change in Stiffness & Day Post AVR & Method & Comments \\
\hline $\begin{array}{l}\text { Barbetseas et al } \\
2006^{9}\end{array}$ & $\begin{array}{l}\text { 3I SAVR, } 52 \% \text { male, mean } \\
\text { age } 67\end{array}$ & $\Leftrightarrow$ & $\uparrow$ & 7 and 180 & $\mathrm{ASi}$ & $\begin{array}{c}\text { No change in stiffness after } 6 \text { months. } \triangle \mathrm{ASi} \\
\text { correlated with AVAi. }\end{array}$ \\
\hline Nemes et al $2007^{10}$ & $\begin{array}{l}12 \text { SAVR, } 58 \% \text { male, mean } \\
\text { age } 65\end{array}$ & $\downarrow$ SBP & $\downarrow$ & 21,180 and 365 & ASi & Gradual decreased ASi with time \\
\hline $\begin{array}{l}\text { Vavuranakis et al } \\
2012^{11}\end{array}$ & $\begin{array}{c}30 \mathrm{TAVI}, 47 \% \text { male, mean } \\
\text { age } 80\end{array}$ & $\uparrow \mathrm{MAP} \Leftrightarrow \mathrm{SBP}$ & $\Leftrightarrow$ & $7-8$ & $\mathrm{ASi}$ & No significant $\Delta$ stiffness nor aortic distensibility \\
\hline Vizzardi et al $2014^{12}$ & $\begin{array}{c}15 \mathrm{TAVI}, 40 \% \text { male, mean } \\
\text { age } 83\end{array}$ & $\Leftrightarrow$ & $\downarrow$ & 180 and 365 & $\mathrm{ASi}$ & $\begin{array}{l}\text { Sustained decreased stiffness after } 12 \text { months } \\
\text { and increased distensibility }\end{array}$ \\
\hline Cantürk et al $2017^{14}$ & $\begin{array}{c}38 \mathrm{SAVR}, 78 \% \text { male, mean } \\
\text { age } 59\end{array}$ & $\Leftrightarrow$ & $\Leftrightarrow$ & 90 & PWV (MOG) & $\begin{array}{c}\text { Baseline PWV was associated with MPG and } \\
\text { AVA. }\end{array}$ \\
\hline $\begin{array}{l}\text { Goudzwaard et al } \\
2019^{15}\end{array}$ & $\begin{array}{c}40 \text { TAVI, } 58 \% \text { male, mean } \\
\text { age } 80\end{array}$ & $\downarrow$ & $\downarrow$ & 1 & PWV and Alx with MOG & $\begin{array}{c}\Delta \mathrm{PWV} \text { was inversely correlated with baseline } \\
\mathrm{PWV}\end{array}$ \\
\hline Yotti et al $2015^{18}$ & $\begin{array}{c}23 \text { TAVI, } 63 \% \text { male, mean } \\
\text { age } 79\end{array}$ & $\uparrow \mathrm{SBP}, \mathrm{DBP}, \mathrm{MAP}$ & $\uparrow$ & 0 & Invasive Alx & $\uparrow$ Vascular load after TAVI \\
\hline $\begin{array}{l}\text { Pagolatou et al } \\
2020^{19}\end{array}$ & $\begin{array}{c}33 \mathrm{TAVl}, 49 \% \text { male, mean } \\
\text { age } 84\end{array}$ & $\uparrow$ aortic BP & $\downarrow$ Alx & 1 & Invasive Alx & \\
\hline Müller et al $2018^{20}$ & $\begin{array}{c}50 \text { TAVI, } 45 \% \text { male, mean } \\
\text { age } 83\end{array}$ & $\Leftrightarrow$ & $\downarrow$ & $2-7$ & Alx (SphygmoCor) & $\downarrow$ Time to peak after TAVI \\
\hline $\begin{array}{l}\text { Terentes-Printzios } \\
\text { et al } 2020^{21}\end{array}$ & $\begin{array}{c}90 \mathrm{TAVI}, 50 \% \text { male, mean } \\
\text { age } 80\end{array}$ & $\Leftrightarrow$ & $\downarrow$ Alx & $1-365$ & Alx (SphygmoCor) & $\begin{array}{l}\downarrow \text { Alx directly after TAVI but no difference after } \\
\qquad \mid \text { year. }\end{array}$ \\
\hline \multirow[t]{2}{*}{ Al Musa et al $2016^{13}$} & $\begin{array}{c}32 \mathrm{TAVI}, 63 \% \text { male, mean } \\
\text { age } 81\end{array}$ & $\Leftrightarrow$ & $\Leftrightarrow$ & 90 & \multirow[t]{2}{*}{ aPWV-MRI } & \multirow[t]{2}{*}{$\begin{array}{l}\text { Also, decreased distensibility ascending/ } \\
\text { descending aorta }\end{array}$} \\
\hline & $\begin{array}{c}40 \text { SAVR, } 78 \% \text { male, mean } \\
\text { age } 73\end{array}$ & $\Leftrightarrow$ & $\uparrow$ & 90 & & \\
\hline \multirow[t]{2}{*}{ Bruschi et al $2016^{24}$} & $\begin{array}{l}15 \text { SAVR, } 60 \% \text { male, mean } \\
\text { age } 77\end{array}$ & $\downarrow \mathrm{SBP}$ & $\Leftrightarrow$ & 7 & \multirow[t]{2}{*}{ cfPWV (Complior) } & \multirow[t]{2}{*}{ cfPWV correlated with $P$ max/mean } \\
\hline & $\begin{array}{c}15 \mathrm{TAVI}, 40 \% \text { male, mean } \\
\text { age } 82\end{array}$ & $\Leftrightarrow$ & $\Leftrightarrow$ & 7 & & \\
\hline $\begin{array}{l}\text { Chirinos JA et al } \\
2019^{22}\end{array}$ & $\begin{array}{c}38 \mathrm{SAVR}, 68 \% \text { male, mean } \\
\text { age } 72\end{array}$ & $\Leftrightarrow$ & $\uparrow c f P W V \uparrow c M R I$ & 180 & $\begin{array}{l}\text { cfPWV (SphygmoCor and } \\
\text { MRI) }\end{array}$ & $\begin{array}{c}\downarrow \text { LV mass, } \uparrow \text { total peripheral resistance, } \downarrow \text { total } \\
\text { arterial compliance }\end{array}$ \\
\hline
\end{tabular}


Table I (Continued).

\begin{tabular}{|c|c|c|c|c|c|c|}
\hline Study & Cohort & Change in SBP & Change in Stiffness & Day Post AVR & Method & Comments \\
\hline $\begin{array}{l}\text { Terentes-Printzios } \\
\text { et al } 2020^{21}\end{array}$ & $\begin{array}{c}90 \text { TAVI, } 50 \% \text { male, mean } \\
\text { age } 80\end{array}$ & $\Leftrightarrow$ & $\uparrow c f / b a P W V \downarrow A l x @ 75$ & 6 and 365 & $\begin{array}{l}\text { cfPWV (Complior), baPWV, } \\
\text { Alx }\end{array}$ & Sustained cf/baPWV after I year. \\
\hline $\begin{array}{l}\text { Raimundo et al } \\
2021^{23}\end{array}$ & $\begin{array}{c}150 \text { SAVR, } 51 \% \text { male, } \\
\text { mean age } 73\end{array}$ & $?$ & $\uparrow$ & $\sim 60$ & cfPWV Complior & $\operatorname{cfPWV} 9.0 \pm 2.1 \rightarrow 9.9 \pm 2.2$ \\
\hline Plunde et al $2021^{7}$ & $\begin{array}{c}32 \text { SAVR, } 67 \% \text { male, mean } \\
\text { age } 69\end{array}$ & $\Leftrightarrow$ & $\Leftrightarrow / \uparrow$ & 3 & $\begin{array}{c}\text { cfPWV (SphygmoCor) CAVI, } \\
\text { baPWV }\end{array}$ & $\uparrow \mathrm{CAVl} / \mathrm{baPWV}, \Leftrightarrow \mathrm{cfPWV}$ \\
\hline
\end{tabular}

Notes: A summary of studies assessing aortic/arterial stiffness before and after aortic valve replacement (AVR). Importantly, this tables incorporate a variety of methods including indirect measures of stiffness such as augmentation index, which is also dependent on other entities. Mobil-O-Graph (MOG) is a highly questioned method to determine arterial stiffness as it is almost entirely dependent on age and systolic blood pressure.

Abbreviations: TAVl, transcatheter aortic valve implantation; SAVR, surgical aortic valve replacement; cfPWV, carotid-femoral pulse wave velocity; Alx, augmentation index; MRI, magnetic resonance imaging; ASi, aortic stiffness index; LV, left ventricle; aPWV, aortic pulse wave velocity. 
an altered pulse wave morphology following AVR. When the obstruction is relieved by AVR, a true arterial stiffness can be measured. Hence, the properties of the arterial wall itself are not changed but rather the ventricular-aorticvascular coupling. Including intrinsic stiffer peripheral arteries may facilitate the detection of a masked increased arterial stiffness.

\section{Arterial Stiffness - in the Long Run}

Arterial stiffness has been followed up to 1 year after AVR (Table 1). The heterogeneity of the studies for the timely proximity to AVR precludes a conclusion on the precise time-course for the changes. However, the changes observed postoperatively were sustained at longer follow-up, albeit numerically attenuated, yet significantly different from the first measurement. This has been reported for both decreased ASi and for increased cfPWV and cMRI PWV. The difference could possibly be explained by a ventricular-arterial coupling optimization ${ }^{26}$ during an adjusting time after the relief of the LV outflow obstruction. Furthermore, it may be of particular importance to capture long term elevated arterial stiffness as it often take years for the LV to recover after AVR. ${ }^{27}$ Future studies should aim at identifying the importance of sustained arterial stiffness after AVR.

\section{Conclusion}

In summary, arterial stiffness is an important contributor to the combined LV load in aortic stenosis. The evaluation of arterial stiffness may have prognostic implications in aortic stenosis and could potentially be implemented in preinterventional risk assessment, in particular for asymptomatic patients. Furthermore, exceptionally low CAVI could be useful in AVS screening. It is important to establish an easy, reliable, and correct measurement of arterial stiffness that may capture the possibly masked arterial stiffness in aortic stenosis. As such, future studies are needed to validate a noninvasive method in aortic stenosis patients and establish the prognostic value of the change in arterial stiffness after aortic valve replacement.

\section{Acknowledgments}

MB was supported by the Swedish Research Council (grant number 2019-01486), the Swedish Heart and Lung Foundation (grant number 20180571), and the King Gustaf V and Queen Victoria Freemason Foundation. OP was supported by the Clinical Scientist Training Programme (CSTP) at Karolinska Institutet.

\section{Disclosure}

The authors report no conflicts of interest in this work.

\section{References}

1. Vlachopoulos C, Aznaouridis K, Stefanadis C. Prediction of cardiovascular events and all-cause mortality with arterial stiffness: a systematic review and meta-analysis. J Am Coll Cardiol. 2010;55(13):1318-1327. doi:10.1016/j.jacc.2009.10.061

2. Hachicha Z, Dumesnil JG, Pibarot P. Usefulness of the valvuloarterial impedance to predict adverse outcome in asymptomatic aortic stenosis. $J$ Am Coll Cardiol. 2009;54(11):1003-1011. doi:10.1016/j.jacc.2009.04.079

3. Sera F, Russo C, Iwata S, et al. Arterial wave reflection and aortic valve calcification in an elderly community-based cohort. $J$ Am Soc Echocardiogr. 2015;28(4):430-436. doi:10.1016/j.echo.2014.12.011

4. Korkmaz L, Ağaç MT, Bektas H, et al. Aortic valve sclerosis is a sign of increased arterial stiffness in clinically asymptomatic subjects. Cardiol $J$. 2013;20(3):318-322. doi:10.5603/cj.2013.0078

5. Saeed S, Saeed N, Grigoryan K, Chowienczyk P, Chambers JB, Rajani R. Determinants and clinical significance of aortic stiffness in patients with moderate or severe aortic stenosis. Int J Cardiol. 2020;315:99-104. doi:10.1016/j.ijcard.2020.03.081

6. Broyd CJ, Patel K, Pugliese F, et al. Pulse wave velocity can be accurately measured during transcatheter aortic valve implantation and used for post-procedure risk stratification. J Hypertens. 2019;37(9):1845-1852. doi:10.1097/hjh.0000000000002141

7. Plunde O, Franco-Cereceda A, Bäck M. Cardiovascular risk factors and hemodynamic measures as determinants of increased arterial stiffness following surgical aortic valve replacement. Front Cardiovasc Med. 2021;8(1808). doi:10.3389/fcvm.2021.754371

8. Chirinos JA, Segers P, Hughes T, Townsend R. Large-artery stiffness in health and disease: JACC state-of-the-art review. J Am Coll Cardiol. 2019;74(9):1237-1263. doi:10.1016/j.jacc.2019.07.012

9. Barbetseas J, Alexopoulos N, Brili S, et al. Changes in aortic root function after valve replacement in patients with aortic stenosis. Int J Cardiol. 2006;110(1):74-79. doi:10.1016/j.ijcard.2005.07.023

10. Nemes A, Galema TW, Geleijnse ML, et al. Aortic valve replacement for aortic stenosis is associated with improved aortic distensibility at long-term follow-up. Am Heart J. 2007;153(1):147-151. doi:10.1016/j.ahj.2006.08.025 
11. Vavuranakis M, Vrachatis DA, Boudoulas H, et al. Effect of transcatheter aortic valve implantation on the ascending aorta's elasticity. Clin Res Cardiol. 2012;101(11):895-899. doi:10.1007/s00392-012-0473-x

12. Vizzardi E, Sciatti E, Bonadei I, et al. Effects of transcatheter aortic valve implantation on ascending aorta wall elastic properties: tissue Doppler imaging and strain Doppler echocardiography study. Int J Cardiol Heart Vessel. 2014;4:198-202. doi:10.1016/j.ijchv.2014.04.003

13. Musa TA, Uddin A, Fairbairn TA, et al. Assessment of aortic stiffness by cardiovascular magnetic resonance following the treatment of severe aortic stenosis by TAVI and surgical AVR. J Cardiovasc Magn Reson. 2016;18(1):37. doi:10.1186/s12968-016-0256-z

14. Canturk E, Cakal B, Karaca O, et al. Changes in aortic pulse wave velocity and the predictors of improvement in arterial stiffness following aortic valve replacement. Ann Thorac Cardiovasc Surg. 2017;23(5):248-255. doi:10.5761/atcs.oa.17-00062

15. Goudzwaard JA, Disegna E, de Ronde-tillmans MJ, Lenzen MJ, de Jaegere PP, Mattace-Raso FU. Short-term changes of blood pressure and aortic stiffness in older patients after transcatheter aortic valve implantation. Clin Interv Aging. 2019;14:1379-1386. doi:10.2147/CIA.S211328

16. Schwartz JE, Feig PU, Izzo JL Jr. Pulse wave velocities derived from cuff ambulatory pulse wave analysis. Hypertension. 2019;74(1):111-116. doi:10.1161/hypertensionaha.119.12756

17. Salvi P, Furlanis G, Grillo A, et al. Unreliable estimation of aortic pulse wave velocity provided by the Mobil-O-Graph algorithm-based system in Marfan syndrome. J Am Heart Assoc. 2019;8(9):e04028. doi:10.1161/jaha.118.011440

18. Yotti R, Bermejo J, Gutierrez-Ibanes E, et al. Systemic vascular load in calcific degenerative aortic valve stenosis: insight from percutaneous valve replacement. J Am Coll Cardiol. 2015;65(5):423-433. doi:10.1016/j.jacc.2014.10.067

19. Pagoulatou S, Stergiopulos N, Bikia V, et al. Acute effects of transcatheter aortic valve replacement on the ventricular-aortic interaction. Am J Physiol Heart Circ Physiol. 2020;319(6):H1451-H1458. doi:10.1152/ajpheart.00451.2020

20. Müller C, Goliasch G, Schachinger S, et al. Transcatheter aortic valve replacement (TAVR) leads to an increase in the subendocardial viability ratio assessed by pulse wave analysis. PLoS One. 2018;13(11):e0207537. doi:10.1371/journal.pone.0207537

21. Terentes-Printzios D, Gardikioti V, Aznaouridis K, et al. The impact of transcatheter aortic valve implantation on arterial stiffness and wave reflections. Int J Cardiol. 2020;323:213-219. doi:10.1016/j.ijcard.2020.08.040

22. Chirinos JA, Akers SR, Schelbert E, et al. Arterial properties as determinants of left ventricular mass and fibrosis in severe aortic stenosis: findings from ACRIN PA 4008. J Am Heart Assoc. 2019;8(1):e010271. doi:10.1161/JAHA.118.010271

23. Raimundo R, Saraiva F, Moreira R, et al. Arterial stiffness changes in severe aortic stenosis patients submitted to valve replacement surgery. Alterações da Rigidez Arterial em Pacientes com Estenose Aórtica Grave Submetidos à Cirurgia de Troca Valvar. Arq Bras Cardiol. 2021;116 (3):475-482. doi:10.36660/abc.20190577

24. Bruschi G, Maloberti A, Sormani P, et al. Arterial stiffness in aortic stenosis: relationship with severity and echocardiographic procedures response. High Blood Press Cardiovasc Prev. 2017;24(1):19-27. doi:10.1007/s40292-016-0176-X

25. Grillo A, Parati G, Rovina M, et al. Short-term repeatability of noninvasive aortic pulse wave velocity assessment: comparison between methods and devices. Am J Hypertens. 2017;31(1):80-88. doi:10.1093/ajh/hpx140

26. Sarajlic P, Friden C, Lund LH, et al. Enhanced ventricular-arterial coupling during a 2-year physical activity programme in patients with rheumatoid arthritis: a prospective substudy of the physical activity in rheumatoid arthritis 2010 trial. J Intern Med. 2018;284(6):664-673. doi:10.1111/joim. 12715

27. Une D, Mesana L, Chan V, et al. Clinical impact of changes in left ventricular function after aortic valve replacement. Circulation. 2015;132 (8):741-747. doi:10.1161/CIRCULATIONAHA.115.015371

\section{Publish your work in this journal}

Vascular Health and Risk Management is an international, peer-reviewed journal of therapeutics and risk management, focusing on concise rapid reporting of clinical studies on the processes involved in the maintenance of vascular health; the monitoring, prevention and treatment of vascular disease and its sequelae; and the involvement of metabolic disorders, particularly diabetes. This journal is indexed on PubMed Central and MedLine. The manuscript management system is completely online and includes a very quick and fair peer-review system, which is all easy to use. Visit http://www.dovepress.com/testimonials.php to read real quotes from published authors.

Submit your manuscript here: https://www.dovepress.com/vascular-health-and-risk-management-journal 